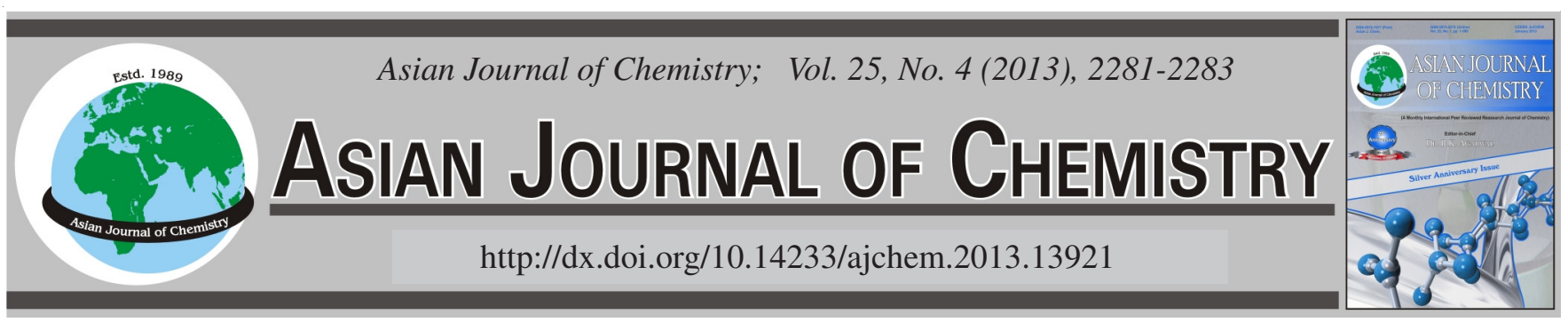

\title{
Regioselectivity of Tin-Mediated Benzylation of Glycoside
}

\author{
XIN LOU
}

Material and Chemical Engineering College, Chuzhou Uniersity, Chuzhou 23900, P.R. China

Corresponding author: Fax: +86 550 3515035; Tel: +86 550 3511052; E-mail: franklinee@ hotmail.com

(Received: 17 April 2012;

Accepted: 22 October 2012)

AJC-12331

Regioselectivity of methyl $\alpha$-D-glucopyranoside benzylation using dibutyltin dimethoxide (DBDM) as stannylating agent was probed, general factors affecting regioselectivity have been examined. The results show the O-2 position of glucoside has advantage of being benzylated over the O-6 position. The major isomers of benzyl ether were separated by preparative HPLC method and characterized.

Key Words: Benzylation, Stannylene acetal, Regioselectivity.

\section{INTRODUCTION}

Benzyl ethers are commonly used for the protection of hydroxyl groups in carbohydrate chemistry since they are stable with respect to both acids and bases and yet are easily removable under mild hydrogenating conditions ${ }^{1-4}$. Consequently, benzylated sugars find wide synthetic application as glycosylating reagents, chiral synthons and pharmaceuticalintermediate ${ }^{5,6}$. Carbohydrate stannylene acetals have proven to be useful intermediates in the regioselective synthesis of carbohydrate derivatives $^{7-10}, 1,6$-dibutylstannylene acetals are reactive intermediates that have been treated with acylating and alkylating agents to provide mono-substituented derivatives of diols or polyols with high regioselectivity ${ }^{11,12}$. However for regioselective substitution of methyl $\alpha$-D-glucoside, the substitution position on pyranoside cycle often varied with detailed condition. For instance, thiophosgene reaction takes place at the 2 and 3 position of glucoside ${ }^{13}$; where allidenation of glucopyranoside occurs across the 4 and 6 positions to give $4,6-O$-allylidene- $\alpha$-D- glucopyranoside ${ }^{14}$; while trimethylsilylation of glucopyrano-side gives only substitution on the 6 position $^{15}$. In this work regioselectivity of glucoside benzylation was probed, dibutyltin dimethoxide was used as the stannylating reagent and benzyl bromide was used as alkylating agent.

\section{EXPERIMENTAL}

${ }^{1} \mathrm{H}$ and ${ }^{13} \mathrm{C}$ spectra were recorded with Varian Inova 300 , 500 NMR spectrometers. ${ }^{1} \mathrm{H}$ chemical shifts in $\mathrm{CD}_{3} \mathrm{OD}$ were referenced to $\mathrm{CHD}_{2} \mathrm{OD}$ (3.30 ppm); ${ }^{13} \mathrm{C}$ chemical shifts in $\mathrm{CD}_{3} \mathrm{OD}$ were referenced to $\mathrm{CHD}_{2} \mathrm{OD}(49.0 \mathrm{ppm})$. FTIR spectra were recorded with a Nicolet FTIR 3000 using either thin film or KBr discs, as specified. Melting points were measured on a STUART melting point apparatus. Elemental analysis was performed on an Exeter analytical CE 440 elemental analyzer. Low and high resolution mass spectra were measured on electrospray mass spectrometry in ES negative mode unless otherwise indicated. TLC was performed on aluminium sheets precoated with Silica Gel $60\left(\mathrm{HF}_{254}\right.$, E. Merck) and spots visualized by UV and charring with $\mathrm{H}_{2} \mathrm{SO}_{4}$-EtOH (1:20).

Benzylation of methyl $\alpha$-D-glucopyr-anoside: Methyl $\alpha$-D-glucopyranoside $(0.97 \mathrm{~g}, 5 \mathrm{mmol})$ was dissolved in the reaction solvent $(40 \mathrm{~mL})$ and dibutyltin dimethoxide $(1.47 \mathrm{~mL}$, $5.5 \mathrm{mmol}$ ) was added to the solution, causing effervescence. The reaction mixture was kept at the required temperature and a solution of benzyl bromide in solvent $(10 \mathrm{~mL})$ was added dropwise over $1 \mathrm{~h}$. The reaction was monitored using TLC and terminated after at least $24 \mathrm{~h}$. The mixture was evaporated under vacuum to give a syrup. This was fractionated by flash chromatography using a solvent mixture of chloroform:methanol (8: 1) to give benzyl ether.

HPLC method development for analysis and separation of isomers of methyl $\alpha$-D-glucopyranoside benzyl ethers: The determination of absorption spectrum of methyl $\alpha$-Dglucopyranoside benzyl ether based on UV studies was found to be $258 \mathrm{~nm}$.

Selection of suitable mobile phase: A series of mobile phases which comprized two or three solvents were investigated. The solution methanol:water (50: 50) was found to be an appropriate solvent system for analysis of benzyl ethers of methyl $\alpha$-D-glucopyranoside. Fig. 1 is a HPLC chromatograph of the reaction mixture from benzylation of methyl $\alpha-D$ glucopyranoside in dioxane, heated at reflux. 


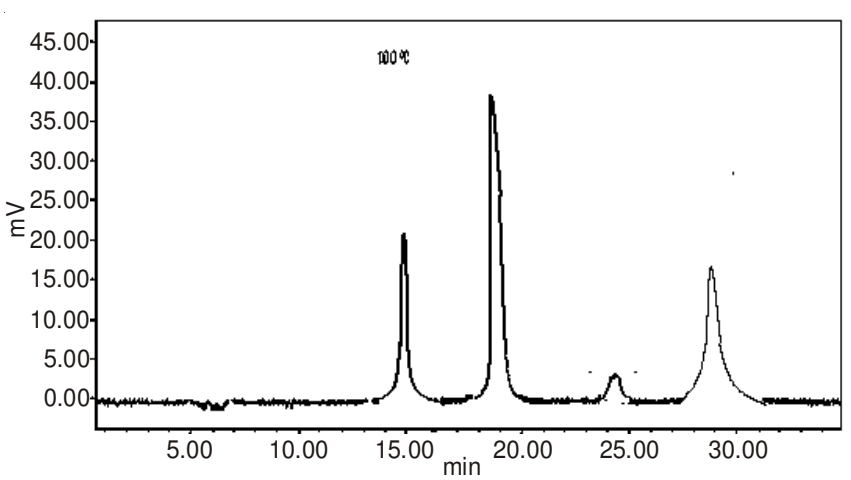

Fig. 1. HPLC-UV chromatograph of benzylation of methyl $\alpha$-Dglucopyranoside using methanol: water $=50: 50$ as the mobile phase; $\mathrm{R}_{1}=14.94, \mathrm{R}_{2}=18.71, \mathrm{R}_{3}=24.45, \mathrm{R}_{4}=28.86 \mathrm{~min} ; \mathrm{A}_{1}: \mathrm{A}_{2}: \mathrm{A}_{3}: \mathrm{A}_{4}$ = 6: 20: 1.6: 11 (R-retention time; A-area of peaks)

It can be seen from Fig. 1 that four isomers were well separated and the retention times of $R_{t 1}=14.94, R_{t 2}=18.71$, $\mathrm{R}_{\mathrm{t} 3}=24.45, \mathrm{R}_{\mathrm{t} 4}=28.86$ min corresponded with the 3-O isomer, 2-O isomer, 4-O isomer, 6-O isomer respectively.

\section{RESULTS AND DISCUSSION}

The initial finding showed that benzylation of methyl $\alpha$ D-glucopyranoside using dibutyltin dimethoxide differs from esterification in that it has to be carried out at higher temperatures, with an excess amount of benzyl bromide (4-6 equiv.). A series of factors were investigated that influence the regioselectivity to probe this reaction.

Effect of solvent on regioselectivity of benzylation of methyl $\alpha$-D-glucopyranoside: The reaction temperature was maintained at $80^{\circ} \mathrm{C}$ and various solvents were investigated to probe the effect on regioselectivity. The effect of addition of a base was also investigated for dioxane and toluene.

Table-1 showed solvents did not obviously affect the regioselectivity, giving 3 or 4 isomers in all cases, while the addition of a base to toluene or dioxane either disimproved regioselectivity or had little effect.

Effect of temperature on regioselectivity of glucoside benzylation: Dioxane was chosen as the solvent for the benzylation reaction. The reaction was carried out at different temperatures to investigate the effect on regioselectivity.

\section{TABLE-1}

EFFECT OF SOLVENT AND NUCLEOPHILE ADDITION ON THE REGIOSELECTIVITY OF BENZYLATION OF METHYL $\alpha$-D-GLUCOPYRANOSIDE USING DBDM

\begin{tabular}{lcccc}
\hline Solvent & Base & $\begin{array}{c}\text { Isomers } \\
\text { numbers }\end{array}$ & $\begin{array}{c}\text { Ratio of } \\
\text { peaks* }\end{array}$ & $\begin{array}{c}\text { Yield of } \\
\text { monoether } \\
(\%)\end{array}$ \\
\hline DMF & & 4 & $6: 4: 2.4: 1$ & 78 \\
Acetonitrile & & 4 & $11: 6: 1.5:$ & 65 \\
Dioxane & & 3 & $10: 4: 1$ & 72 \\
Dioxane & DMAP & 4 & $2: 1.7: 1: 1$ & 87 \\
DME & & 3 & $3: 1.5: 1$ & 61 \\
Toluene & & 4 & $4: 3: 2: 1$ & 48 \\
Toluene & TEA & 4 & $2: 1.5: 1: 1$ & 58 \\
\hline
\end{tabular}

*Ratio of isomers was detected by HPLC using Method G, Reaction conditions: Methyl $\alpha$-D-glucopyranoside: DBDM: benzyl bromide $=1: 1.1: 4, \mathrm{~T}: 80{ }^{\circ} \mathrm{C}$, Peaks are in the order of decreasing composition, Rts for these peaks are 19.11, 28.86, 15.44, $24.45 \mathrm{~min}$
Table- 2 showed that the increasing temperature leads to an increased yield of monoether, however there is reduced regioselectivity. Possibly the various stannylene acetals of methyl $\alpha$-D-glucopyranoside migrate more easily between different vicinal diol systems at higher temperatures and so a mixture of isomers is given.

\begin{tabular}{ccc} 
TABLE-2 \\
EFFECT OF TEMPERATURE ON REGIOSELECTIVITY OF \\
\multicolumn{2}{c}{ TIN-MEDIATED BENZYLATION REACTION } \\
\hline Temperature $\left({ }^{\circ} \mathrm{C}\right)$ & Ratio of isomers* & $\begin{array}{c}\text { Overall yield of } \\
\text { monoethers }(\%)\end{array}$ \\
\hline Heated at reflux & $20: 11: 6: 1$ & 85 \\
$80^{\circ} \mathrm{C}$ & $10: 4: 1$ & 72 \\
$60^{\circ} \mathrm{C}$ & $2.6: 1$ & 61 \\
$40^{\circ} \mathrm{C}$ & N/A & 3 \\
\hline
\end{tabular}

Ratio of isomers was detected by HPLC using method G (mobile phase: methanol: water $=50: 50$, flow rate $=1.0 \mathrm{~mL} / \mathrm{min}$, UV detector), Reaction conditions: methyl $\alpha$-D-glucopyranoside: DBDM: benzyl bromide $=1: 1.1: 4$, solvent: dioxane. Peaks are in the order of decreasing composition, Rts for these peaks are 19.11, 28.86, 15.44, $24.45 \mathrm{~min}$

Following optimization of the reaction conditions (temperature: $60{ }^{\circ} \mathrm{C}$; solvent: dioxane), we found the reaction gave a mixture of 2-O and 6-O isomers in a ratio of 2.6: $1 .{ }^{13} \mathrm{C}$ NMR was used to elucidate the structure of the mixture of methyl $\alpha$-D-glucopyranoside benzyl ether isomers, comparison of these data with the NMR data for esterification indicates benzylation has a much greater effect on ${ }^{13} \mathrm{C}$ shift of the substituted carbons (+7.5-8.2 ppm) than esterification (2-3 ppm). It is worthy of mention that the $\mathrm{H}-2$ of the O-2 isomer and $\mathrm{H}-6$ of the 6-O isomer is nearly unchanged, which is not the case for esterification, where we found that the $\mathrm{H}-2 \mathrm{had}$ a shift of 1.1-1.2 ppm for all the methyl 2-O-acyl- $\alpha$-D-glucopyranosides $^{12}$.

Methyl 2-O-benzyl- $\alpha$-D-glucopyranoside: yield $47.4 \%$; ${ }^{1} \mathrm{H}$ NMR $\left(500 \mathrm{MHz}, \mathrm{CD}_{3} \mathrm{OD}\right): \delta 7.38-7.22(\mathrm{~m}, 5 \mathrm{H}$, aromatic $\mathrm{H}), 4.72(\mathrm{~d}, 1 \mathrm{H}, J=12.0 \mathrm{~Hz}, \mathrm{CHaPh}), 4.64\left(\mathrm{~d}, 1 \mathrm{H}, J_{1,2}=3.6\right.$ $\mathrm{Hz}, \mathrm{H}-1), 4.63$ (d, 1H, J = 12.0 Hz, CHbPh), 3.79 (dd, 1H, $J_{5}$, $\left.6 \mathrm{a}=2.4 \mathrm{~Hz}, J_{6 \mathrm{a}, 6 \mathrm{~b}}=11.7 \mathrm{~Hz}, \mathrm{H}-6 \mathrm{a}\right), 3.74\left(\mathrm{apt} \mathrm{t}, 1 \mathrm{H}, J_{2,3}=J_{3,4}=\right.$ $9.5 \mathrm{~Hz}, \mathrm{H}-3), 3.65$ (dd, $1 \mathrm{H}, J_{5,6 \mathrm{~b}}=5.5 \mathrm{~Hz}, J_{6 \mathrm{a}, 6 \mathrm{~b}}=11.7 \mathrm{~Hz}, \mathrm{H}-$ 6b), 3.49 (ddd, $1 \mathrm{H}, J_{5,6 \mathrm{a}}=2.4 \mathrm{~Hz}, J_{5,6 \mathrm{~b}}=5.5 \mathrm{~Hz}, J_{4,5}=9.5 \mathrm{~Hz}$, H-5), 3.33 (s, $\left.3 \mathrm{H}, \mathrm{OCH}_{3}\right), 3.32\left(\mathrm{dd}, 1 \mathrm{H}, J_{1,2}=3.6 \mathrm{~Hz}, J_{2,3}=9.5\right.$ $\mathrm{Hz}, \mathrm{H}-2$ ), 3.30 (apt t, $\left.1 \mathrm{H}, J_{3,4}=J_{4,5}=9.5 \mathrm{~Hz}, \mathrm{H}-4\right) ;{ }^{13} \mathrm{C}$ NMR (500 MHz, CD $\left.{ }_{3} \mathrm{OD}\right): \delta 139.9,129.4,129.4,129.3,129.3,128.9$ (aromatic C), $99.4(\mathrm{C}-1), 81.1(\mathrm{C}-2), 74.4\left(\mathrm{CH}_{2} \mathrm{Ph}\right), 74.1(\mathrm{C}-$ 3), $73.4(\mathrm{C}-5), 71.9(\mathrm{C}-4), 62.7(\mathrm{C}-6), 55.4\left(\mathrm{OCH}_{3}\right)$; CI-LRMS: Found 284.1 required 284.1.

Methyl 6-O-benzyl- $\boldsymbol{\alpha}$-D-glucopyranoside: Yield $15.8 \%$; ${ }^{1} \mathrm{H}$ NMR (500 MHz, $\left.\mathrm{CD}_{3} \mathrm{OD}\right): \delta$ 7.38-7.22 (m, 5H, aromatic $\mathrm{H}), 4.72(\mathrm{~d}, 1 \mathrm{H}, J=12.0 \mathrm{~Hz}, \mathrm{CHaPh}), 4.66\left(\mathrm{~d}, 1 \mathrm{H}, J_{1,2}=3.7\right.$ $\mathrm{Hz}, \mathrm{H}-1), 4.63$ (d, 1H, J = 12.0 Hz, CHbPh), 3.80 (dd, 1H, $J_{5,6 \mathrm{a}}$ $\left.=2.5 \mathrm{~Hz}, J_{6 \mathrm{a}, 6 \mathrm{~b}}=11.8 \mathrm{~Hz}, \mathrm{H}-6 \mathrm{a}\right), 3.67\left(\mathrm{dd}, 1 \mathrm{H}, J_{5,6 \mathrm{~b}}=5.7 \mathrm{~Hz}\right.$, $\left.J_{6 \mathrm{a}, 6 \mathrm{~b}}=11.9 \mathrm{~Hz}, \mathrm{H}-6 \mathrm{~b}\right), 3.61$ (apt t, $1 \mathrm{H}, J_{2,3}=J_{3,4}=9.2 \mathrm{~Hz}, \mathrm{H}-$ 3), $3.52\left(\mathrm{ddd}, 1 \mathrm{H}, J_{5,6 \mathrm{a}}=2.4 \mathrm{~Hz}, J_{5,6 \mathrm{~b}}=5.4 \mathrm{~Hz}, J_{4,5}=9.9 \mathrm{~Hz}, \mathrm{H}-\right.$ 5), 3.4 (s, 3H, OCH3), $3.39\left(\mathrm{dd}, 1 \mathrm{H}, J_{1,2}=3.7 \mathrm{~Hz}, J_{2,3}=9.2\right.$ $\mathrm{Hz}, \mathrm{H}-2$ ), 3.37 (apt t, $\left.1 \mathrm{H}, J_{3,4}=J_{4,5}=9.2 \mathrm{~Hz}, \mathrm{H}-4\right) ;{ }^{13} \mathrm{C} \mathrm{NMR}$ (500 MHz, $\left.\mathrm{CD}_{3} \mathrm{OD}\right): \delta 139.76,129.39,129.39,128.85,128.85$, 128.68 (aromatic C), 101.38 (C-1), 75.23 (C-3), 74.56 
$\left(\mathrm{CH}_{2} \mathrm{Ph}\right), 73.56$ (C-2), 72.58 (C-5), 71.96 (C-4), 70.93 (C-6), $55.69\left(\mathrm{OCH}_{3}\right)$; CI-LRMS: Found 284.1 required 284.1.

\section{ACKNOWLEDGEMENTS}

This work was supported by Project of State Key Lab of Chinese Pharmaceutical Process Technology SKL2010M0303, Provincial-level University Research Projects in Anhui Province KJ2011Z275 and Anhui Provincial-level Chemical Engineering and Technology Teaching Team 20101035 . Thanks also due to Dr. Seamas Cassidy and Prof. Gary Henehan in DIT, Ireland for their suggestions during this work.

\section{REFERENCES}

1. C.B. Reese, in ed.: J.F.W. McOmie, Protective Groups in Organic Chemistry, Plenum Press, London (1973).

2. T. Green, Protective Groups in Organic Synthesis, John Wiley \& Sons, NY, 29 (1981).
3. C.M. McCloskey, Adv. Carbohyd. Chem., 12, 137 (1957).

4. R.W. Binkley and H.G. Ambrose, J. Carbohyd. Chem., 3, 1 (1984).

5. H. Paulsen, Angew. Chem. Int. Ed., 21, 155 (1982).

6. R.R. Schmidt, Angew. Chem. Int. Ed., 25, 212 (1986).

7. S. David and S. Hanessian, Tetrahedron, 41, 643 (1985).

8. M. Pereyre, J.-P. Quintard and A. Rahm, London: Butterworths, Chap. 11 (1987).

9. T.B. Grindley and D.C. Washington, ACS, Chap. 4 (1994).

10. S. Hannesian, Preparative Carbohydrate Chemistry. New York: Marcel Dekker Inc., Chap. 4 (1997).

11. A.G. Goncalves, M.D. Noseda, M.E.R. Duarte and T.B. Grindly, J. Org. Chem., 72, 9896 (2007).

12. X. Lou, J. O'Brien, G. Henehan and S. Cassidy, Asian J. Chem., 22, 3135 (2010).

13. M.W. Bredenkamp, C.W. Holzapfel and F.S. Toerian, Afr. J. Chem., 44, 97 (1991).

14. C.W. Holzapfel, J.J. Huyser, V.T.L. Merwe and F.R. Heerden, Heterocycles, 32, 1445 (1991).

15. M.W.S. Bredenkamp, Afr. J. Chem., 48, 154 (1995). 